\title{
Kalium Hydroxide/Zirconia Pillared Bentonite for Palm Oil Transesterification
}

\author{
YESLIA UTUBIRA ${ }^{1,2}$, KARNA WIJAYA ${ }^{1 *}$, TRIYONOL ${ }^{1}$ and EKO SRI KUNARTI ${ }^{1}$ \\ ${ }^{1}$ Chemistry Department, Faculty of Mathematics and Natural Sciences Gadjah Mada University, \\ Yogyakarta 55281, Indonesia. \\ ${ }^{2}$ Department of Chemistry Education, Faculty of Teacher Training and Educational Sciences, \\ Pattimura University, Ambon 97234, Indonesia. \\ *Corresponding author E-mail: karnawijaya@ugm.ac.id \\ http://dx.doi.org/10.13005/ojc/340339
}

(Received: Janurary 11, 2018; Accepted: May 02, 2018)

\begin{abstract}
The aim of this study is to produce biodiesel from palm oil using heterogeneous catalyst i.e. $\mathrm{KOH} / \mathrm{ZrO}_{2}$-Bentonite. The catalyst was prepared through $\mathrm{KOH}$ impregnation on $\mathrm{ZrO}_{2}$ - Bentonite with a ratio between $\mathrm{KOH}: \mathrm{ZrO}_{2}$-Bentonite was $20-30 \mathrm{wt} \%$. Afterwards, it was followed by the heating process using microwave radiation $700 \mathrm{~W}$ for 10 minutes Based on the result of the characterization using XRD, Gas Sorption Analyzer, FTIR and SEM-EDX, the best performance for the ratio of $\mathrm{KOH}: \mathrm{ZrO}_{2}-$ Bentonite of the process was on $25 \mathrm{wt} \%$. The catalytic activity test on palm oil transesterification resulted methyl ester as much as $81 \%$ on the reaction condition of $65^{\circ} \mathrm{C}$ for three hours. In addition, the amount of catalyst-used was as much as $3 \%$ of the oil weight. The result of ASTM test showed that the methyl ester product from palm oil fulfills the National Test Standard for Diesel Oil referring to SNI 04-7182-2006.
\end{abstract}

Keywords: $\mathrm{KOH}, \mathrm{ZrO}_{2}$-Bentonite, Palm oil, Transesterification.

\section{INTRODUCTION}

Biodiesel is an alternative energy used for diesel engine. Its characteristics are biodegradable, non-toxic, and environmental friendly. Biodiesel can be produced through transesterification of vegetable oil and animal fatty acid using alcohol and base catalyst; such as $\mathrm{KOH}, \mathrm{NaOH}$ or methoxide ${ }^{1}$. The use of homogeneous catalyst for the process has been reported a lot; however, its usage has negative effects including long term regeneration time and producing a lot of toxic waste.

The use of clay as the heterogeneous catalyst has been more promising because of its positive effect including the ease of separation process between the product and the catalyst, easy to regenerate, more efficient, cheap and environmental friendly ${ }^{2-5}$. The use of heterogeneous solid catalyst from modified clay has been proven

This is an Open Access article licensed under a Creative Commons Attribution-Non Commercial-Share Alike 4.0 International License (https://creativecommons.org/licenses/by-nc-sa/4.0/), which permits unrestricted Non Commercial use, distribution and reproduction in any medium, provided the original work is properly cited. 
to be used in biodiesel production through transesterification process ${ }^{6}$. Base alkaline can be used as heterogeneous base catalyst if it is impregnated on supporting material. Base alkaline; such as: $\mathrm{NaOH}$ and $\mathrm{KOH}$, is very sensitive towards free fatty acid included on oil and it is effective for transesterification process. The use of base $\mathrm{KOH}$ combined with supported material (alumina, $\mathrm{NaY}, \mathrm{MCM}-4$, zeolite) as heterogeneous catalyst in transesterification process is more promising. It has been used by several researchers ${ }^{7-10}$. Transesterification process of palm oil using continuous reactor, $\mathrm{KOH} /$ bentonite catalyst variated on $\mathrm{KOH}$ amount and impregnated as much as $5-25$ wt $\%$, has been successfully done. $\mathrm{KOH}$ impregnation of $20 \mathrm{wt} \%$ on bentonite has been reported that it has heterogeneous catalytic characteristics with mesoporous structure in which the biodiesel yield is higher than $75 \%$ on reaction condition of $60{ }^{\circ} \mathrm{C}$, oil/metanol mol ratio of $1: 15$, and rate of $0,3 \mathrm{~mL}$. $\mathrm{min}^{-1}$ and active for seven days ${ }^{10}$.

The use of Indonesia natural clay as a supporting material on synthesis of heterogeneous catalyst is reached with $\mathrm{KOH} /$ bentonite ratio 1:4. For impregnation process, weight catalyst-used on transesterification process is as much as $3 \%$ with temperature $60^{\circ} \mathrm{C}$, oil/methanol ratio $1: 6$, and the process takes three hours, $90,7 \%$ of biodiesel yield ${ }^{3}$. This was also found for transesterification palm oil using $\mathrm{KOH} / \mathrm{Al}_{2} \mathrm{O}_{3}$ and $\mathrm{KOH} / \mathrm{NaY}$ catalyst ${ }^{7}$. It can be concluded that the total amount of impregnated $\mathrm{KOH}$ influences on an existing of $\mathrm{K}$ and $\mathrm{O}$ activated site in catalyst. As a result, it affects biodiesel yield. The high amount of $\mathrm{KOH}$ will strengthen the interaction between $\mathrm{KOH}$ and internal bentonite layer and the calcination process produced Al-O-K group forming. This formed-group has a lower catalytic activity than alkaline $\mathrm{K}_{2} \mathrm{O}$ thus it affects the yield of biodiesel. $\mathrm{K}_{2} \mathrm{O}$-formed due to dihydroxylation of $\mathrm{OH}$ groups contributes to the catalytic properties of these materials, besides the formation of $\mathrm{K}_{2} \mathrm{O}$; as a result of the merger of ions $\mathrm{K}+$ into a vacant site of zirconia with a hydroxyl group, formed K-O-Zr on the surface after the calcined process ${ }^{11}$. Several studies have reported the presence of $\mathrm{K}_{2} \mathrm{O}$ groups play an important role in improving the performance of the catalyst for the production of biodiese $\left.\right|^{10}$. In this study, synthesized heterogeneous base catalyst $\mathrm{KOH} /$ $\mathrm{ZrO}_{2}$-Bentonite was used by varying the amount of
$\mathrm{KOH}$ is impregnated to obtain a base catalyst which has high catalytic activity for the transesterification reaction of palm oil. The catalyst activity will increase as the base sites for impregnation $\mathrm{KOH}$ increased.

\section{MATERIALS AND METHODS}

Chemical Substances. The materials used in this study were natural Bentonite, $\mathrm{ZrOCl}_{2} \bullet 8 \mathrm{H}_{2} \mathrm{O}$ and $\mathrm{AgNO}_{3}, \mathrm{KOH}$ (E. Merck \& $\mathrm{Co}$ ), distilled water, methanol (E. Merck \& Co.) and Palm oil.

The instruments used include a set of glassware, centrifuge (KOKUSAN H-107), an oven (Memmert), porcelain cup, an analytical balance porcelain mortar and mortar, the 200 mesh sieve, and microwave. Diffraction patterns recorded on a XRD-6000 Shimadzu, using CuK $\alpha$ powder irradiated by the $\lambda=0.5406 \AA$. FTIR spectra were performed on PC 8201 infrared spectrophotometer (Shimadzu) used $\mathrm{KBr}$ pellet at room temperature. $\mathrm{N}^{2}$ adsorptiondesorption isotherms were measured at liquid nitrogen temperature with a gas sorption analyzer (Quantachrome, Autosorb-1). The morphology and elemental analysis of the test samples were estimated by Scanning electron microscopy with energy dispersive X-ray spectroscopy (SEM-EDX ZEISS EVO MA 10).

\section{Procedure}

$\mathrm{KOH}$ impregnation on $\mathrm{ZrO}_{2}$-Bentonite

$\mathrm{ZrO}_{2}$-Bentonite was impregnated using $\mathrm{KOH}(20-30 \mathrm{wt} \%)$ solution and stirred for $24 \mathrm{~h}$ at room temperature. Then it was filtered and dried in an oven temperature of $70^{\circ} \mathrm{C}$ for $24 \mathrm{~h}$, Next, it was proceed with the calcination of $700 \mathrm{~W}$ microwave radiation for 10 minute. The impregnation results were labeled using $20 \% \mathrm{KOH} / \mathrm{ZrO}_{2}$-Bent, $25 \% \mathrm{KOH} /$ $\mathrm{ZrO}_{2}$-Bent and $30 \% \mathrm{KOH} / \mathrm{ZrO}_{2}$-Bent. The results were characterized by XRD, Gas sorption Analyzer, FTIR, SEM-EDX.

\section{Transesterification Palm Oil using $\mathrm{KOH} / \mathrm{ZrO}_{2}-$ Bentonite}

Methanol and oil are entered into a three-neck flask ( $250 \mathrm{~mL}$ capacity) with a molar ratio of $12: 1$ and $3 \%$ by the weight of the catalyst $\mathrm{KOH} / \mathrm{ZrO}_{2}$-Bentonite. The reaction was conducted at a temperature of $65^{\circ} \mathrm{C}$ for $3 \mathrm{~h}$, Further more, the catalyst was separated by centrifugation. Then the 
mixture was put in a separating funnel and allowed to stand overnight to separate between methyl ester and glycerol. Methyl ester production was then washed with distillated hot aqua water and $\mathrm{Na}_{2} \mathrm{SO}_{4}$ was added into it. Methyl esters (biodiesel) were analyzed for its: density, viscosity, pour point, flash point, and heat of combustion. The analysis was determined by the method of the American Standard for Testing Materials (ASTM).

\section{RESULTS AND DISCUSSION}

\section{Characterization of $\mathrm{KOH} / \mathrm{ZrO}_{2}$-Bentonite with XRD}

The analysis of the $\mathrm{KOH} / \mathrm{ZrO}_{2}$-Bentonite catalyst used XRD to determine impregnation effect of $\mathrm{KOH}$ towards the crystallinity of $\mathrm{ZrO}_{2}$-Bentonite. The results of $\mathrm{X}$-ray diffraction analysis of $\mathrm{KOH} / \mathrm{ZrO}_{2}-$ Bentonite were shown in Fig. 1. The XRD pattern of the $\mathrm{KOH} / \mathrm{ZrO}_{2}$-Bentonite shows the characteristics of zirconia pillared bentonite. In the total loading of $\mathrm{KOH} 20 \mathrm{wt} \%$, the XRD patterns, the catalyst were still quite similar to the pillared bentonite samples and a new phase of $\mathrm{K}_{2} \mathrm{O}$ began to emerge.

The similar XRD patterns were also observed when the amount of impregnated $\mathrm{KOH}$ increasing to $25 \mathrm{wt} \%$, crystallinity of catalyst increased. This indicates that during the process of $\mathrm{KOH}$ impregnation, coating/bentonite's pillar is not physically damaged but able to absorb potassium molecules on the surface ${ }^{10}$. This is shown by the

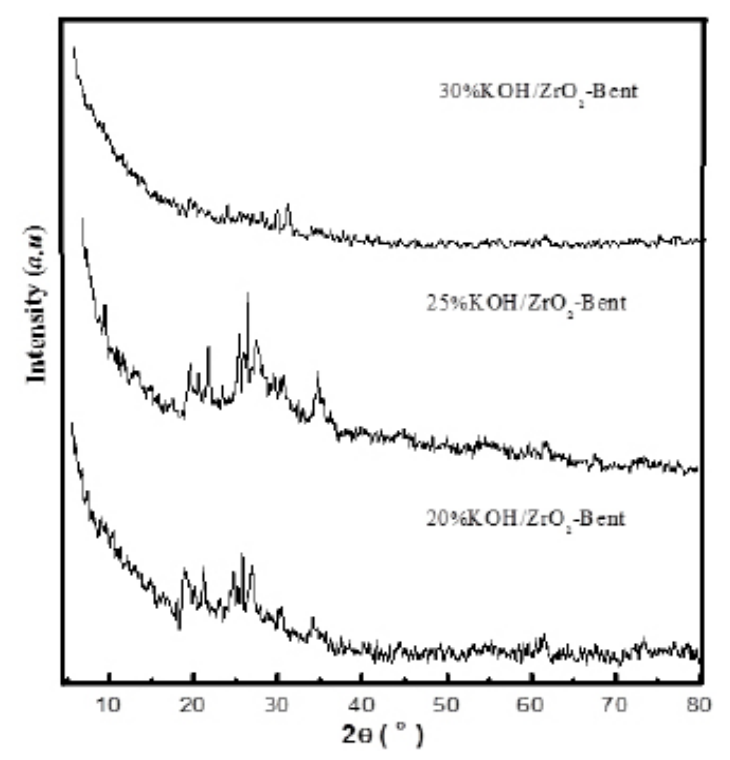

Fig. 1. XRD pattern of $\mathrm{KOH} / \mathrm{ZrO}_{2}$-Bentonite increasing intensity of the diffraction pattern of $\mathrm{K}_{2} \mathrm{O}$ observed at $2 \theta=23^{\circ}, 27^{\circ}, 31^{\circ}, 39^{\circ}, 46^{\circ}, 48^{\circ}, 57^{\circ}$, and

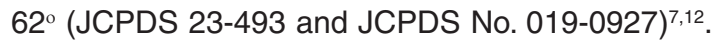
However, the crystallinity of the catalyst decreased with increasing amount of $\mathrm{KOH}$ that fell to $30 \mathrm{wt} \%$ where the intensity of the XRD pattern declined.

The diffractogram peak of $\mathrm{K}_{2} \mathrm{O}$ was very low compared with the prior XRD patterns of catalyst and pillared bentonite material, or there occurred an overlap with the reflection of the carrier material ${ }^{10}$. The formation of identified $\mathrm{K}_{2} \mathrm{O}$ through XRD instrumentation on the $\mathrm{KOH} / \mathrm{ZrO}_{2}$-Bentonite showed the ununiformed dispersion of $\mathrm{KOH}$ dispersion either on the surface or part of pillared bentonite's structure, which through a calcination process will turn into $\mathrm{K}_{2} \mathrm{O}$. The $\mathrm{K}_{2} \mathrm{O}$ phase plays an important role in improving the performance of the catalyst for the production of biodiesel $^{7,12}$.

\section{Analysis of Functional Group with FTIR}

Analysis of FTIR (Fig. 2) showed the impregnation of $\mathrm{KOH}$ in $\mathrm{ZrO}_{2}$-pillared bentonite ( $\mathrm{ZrO}_{2}$-Bentonite) afffected its material structure in which the occurrence intensity modification on some peaks of $\mathrm{KOH} / \mathrm{ZrO}_{2}$-Bentonite. The absorption peak of wave number of $470 \mathrm{~cm}^{-1}$ decreased the intensity ${ }^{4}$, and shifted to a wave number of $462 \mathrm{~cm}^{-1}$. It indicates the formation of Si-OK bond, shown by widening band on absorption wave number of $3441 \mathrm{~cm}-1$ that shifted to the wave number of $3425 \mathrm{~cm}^{-1}$. The intensity of the absorption band at wave number of $1635 \mathrm{~cm}^{-1}$ which was the vibration $-\mathrm{OH} 14,15$, increased at the spectra of $30 \% \mathrm{KOH} / \mathrm{ZrO}_{2}-$ Bent because of $\mathrm{KOH}$ impregnation process. The shifting absorption of wave number of $1041 \mathrm{~cm}^{-1}$ on the material $\mathrm{ZrO}_{2}-$ Bentonite $^{12}$ to a wave number of $1033 \mathrm{~cm}^{-1}$ is predicted due to the bound metal cation of $\mathrm{K}$ on the cluster $\mathrm{Si}-\mathrm{O}-\mathrm{H}$, to form Si-O-K. Based on the results of FTIR analysis, $\mathrm{KOH}$ impregnation of $20-30 \mathrm{wt} \%$ shows that the impregnation process was successful as shown by the sharpening of the absorption band at wave number of $1373 \mathrm{~cm}^{-1}$ which is the absorption of $\mathrm{K}-\mathrm{O}$ and $\mathrm{Zr}-\mathrm{O}-\mathrm{K}$ bond11 that does not exist in $\mathrm{ZrO}_{2}-$ Bentonite ${ }^{14}$. 


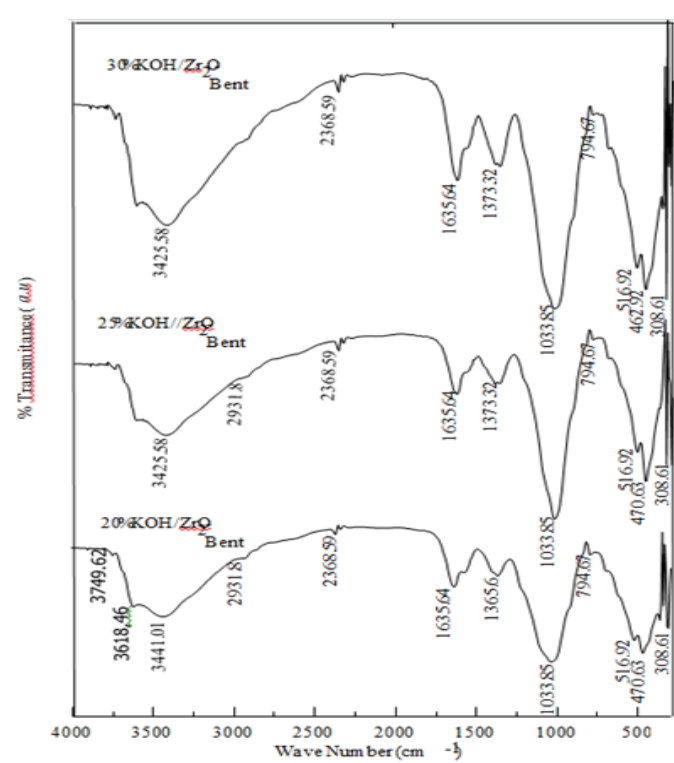

Fig. 2. FTIR spectra of $\mathrm{KOH} / \mathrm{ZrO}_{2}$-Bentonite

\section{Analysis of Surface Area and Porosity}

The analysis of catalyst's surface area used Gas Sorption Analysis (GSA), analysis of total volume of pore was determined based on the value of pore volume at $\mathrm{P} / \mathrm{P}^{\circ} \sim 1$ and the result is shown on the Table 1.

The analysis result showed that the impregnation of $\mathrm{KOH}$ into the $\mathrm{ZrO}_{2}$-Bentonite material decreased the specific surface area and total pore volume and increases the pore's average diameter. The specific surface area of $20 \%$ $\mathrm{KOH} / \mathrm{ZrO}_{2}$-Bent, $25 \% \mathrm{KOH} / \mathrm{ZrO}_{2}$-Bent and $30 \%$ $\mathrm{KOH} / \mathrm{ZrO}_{2}$-Bent are $10.207,11.639$ and 2.983 $\mathrm{m}^{2} \cdot \mathrm{g}^{-1}$ respectively. The ratio of surface area decreases as the increasing ratio of impregnated $\mathrm{KOH}$ in $\mathrm{ZrO}_{2}$-Bentonite material. It indicates that $\mathrm{KOH}$ penetrated into the pores of $\mathrm{ZrO}_{2}$-Bentonite which causes a reduction of the surface area of the catalyst ${ }^{3}$. All catalysts show the typical type IV of adsorption isotherm type and type $\mathrm{H} 1$ of hysteresis loop, which is characteristic of mesoporous material with pore diameters $>20 \AA$ ), as shown in Fig. $3^{10,16}$.

These results indicate that the catalyst $\mathrm{KOH} / \mathrm{ZrO}_{2}-$ Bentonite can be used as a heterogeneous base catalysts in the transesterification of palm oil.

Table 1: The Analysis Result of Nitrogen Gas Adsorption

\begin{tabular}{lccc} 
& Spesific & Total Pore & Pore \\
\hline Sample & $\begin{array}{c}\text { Surface Area } \\
\left(\mathrm{m}^{2} \cdot \mathrm{g}^{-1}\right)\end{array}$ & $\begin{array}{c}\text { Volume } \\
\left(\mathrm{cm}^{3} \cdot \mathrm{g}^{-1}\right)\end{array}$ & $\begin{array}{c}\text { diameter, } \\
(\AA)\end{array}$ \\
\hline $20 \% \mathrm{KOH} / \mathrm{ZrO}_{2}$-Bent & 10.207 & 0.076 & 38.296 \\
$25 \% \mathrm{KOH} / \mathrm{ZrO}_{2}$-Bent & 11.639 & 0.064 & 37.715 \\
$30 \% \mathrm{KOH} / \mathrm{ZrO}_{2}$-Bent & 2.983 & 0.059 & 37.776 \\
\hline
\end{tabular}

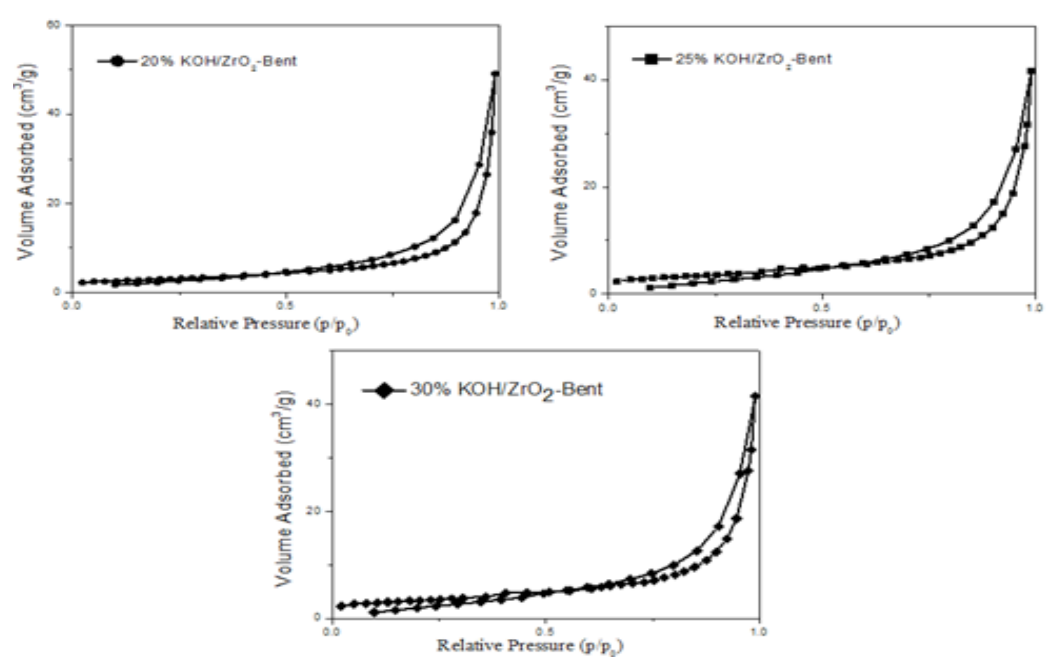

Fig. 3. Nitrogen Sorption Isotherms of $\mathrm{KOH} / \mathrm{ZrO}_{2}$-Bentonite 
Distribution of pore size in $25 \% \mathrm{KOH} /$ $\mathrm{ZrO}_{2}$-Bent is more homogeneous than in the two other (Fig. 4). The addition of $\mathrm{KOH}$ on zirconia pillared bentonite material closed the small pores and even led to the closure of the pore-porous so it only contains the large pores.
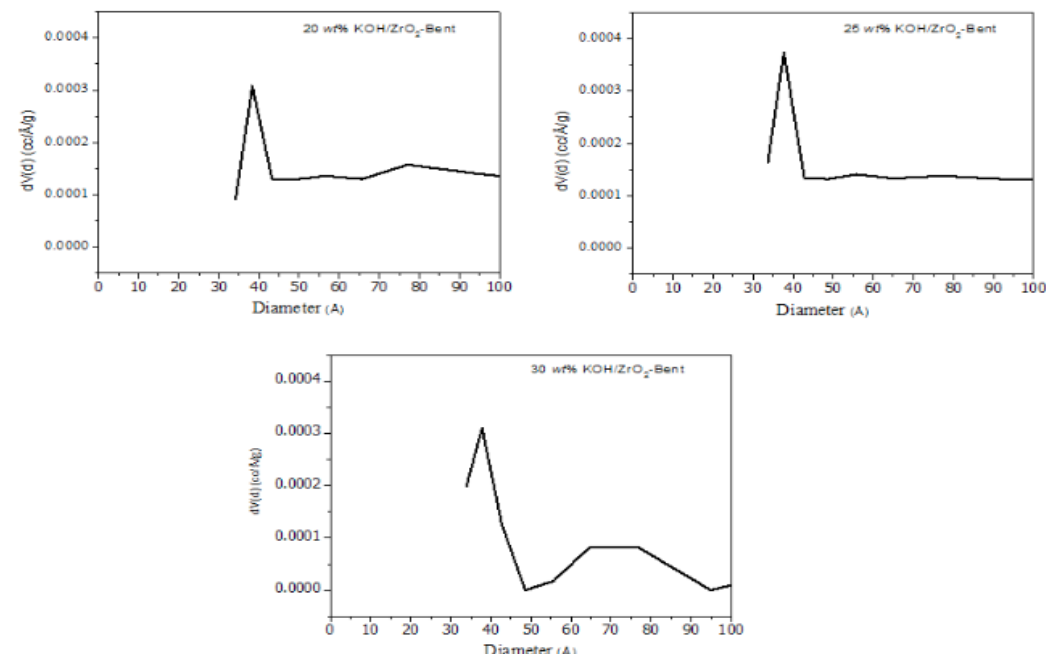

Fig. 4. Pore size distribution of $\mathrm{KOH} / \mathrm{ZrO}_{2}$-Bentonite

\section{SEM - EDX Analysis}

The success of impregnation process can also be observed by using SEM to investigate the morphology of the modified bentonite. Catalyst morphology of $\mathrm{KOH} / \mathrm{ZrO}_{2}$-Bentonite using SEM (Fig. 5) showed grooves providing the distinctiveness of zirconia, pillared bentonite 17. After $\mathrm{ZrO}_{2}$-Bentonite is impregnated with $\mathrm{KOH}$, it shows the presence of potassium oxide granules on the surface. SEM images revealed that $\mathrm{KOH} / \mathrm{ZrO}_{2}$-Bentonite is irregular in shape at $20000 x$ magnification which is shown in Figure. 5 (a-c).

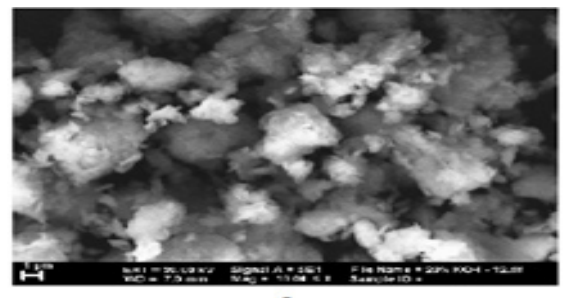

a

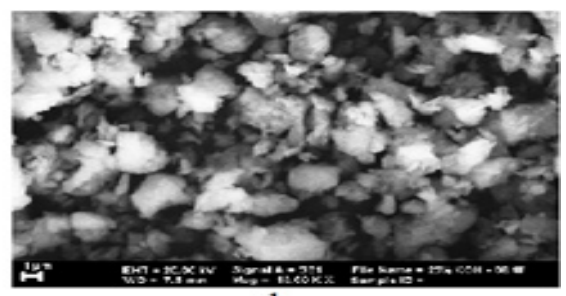

b

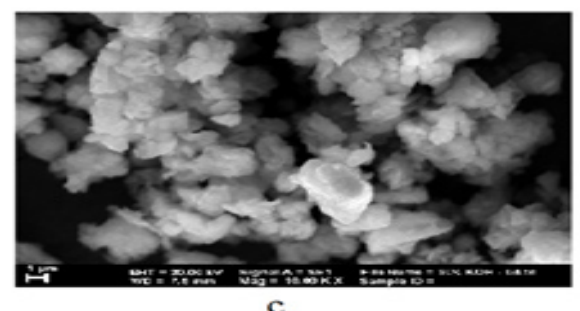

Fig. 5. SEM profile of (a) $20 \% \mathrm{KOH} / \mathrm{ZrO}_{2}$-Bent, (b) $25 \% \mathrm{KOH} / \mathrm{ZrO}{ }_{2}$-Bent, (c) $30 \% \mathrm{KOH} / \mathrm{ZrO}{ }_{2}$-Bent

After the $\mathrm{KOH}$ impregnation, the particles seem to form aggregates. When loading $\mathrm{KOH} 20 \%$ by weight, the surface-modified bentonite showed crystallinity which is similar to $\mathrm{ZrO}_{2}-$-Bentonite. There was a reduction in the particle size of the catalyst as a result of the imposition of $\mathrm{KOH}$. However, no significant differences were observed between the three catalysts. It shows a good dispersion of $\mathrm{KOH}$ on the surface of $\mathrm{ZrO}_{2}$-Bentonite for loading $\mathrm{KOH} 25$ $w t \%$, the morphology of the catalyst has greater pores between the particles of the $20 \% \mathrm{KOH} / \mathrm{ZrO}_{2}$-Bent and $30 \% \mathrm{KOH} / \mathrm{ZrO}_{2}-$-Bent. The more homogeneous it is 
(Fig. 5a, 5c) it leads to increased contact between the catalyst and the substrate, there by increasing the catalytic ability in the transesterification reaction ${ }^{18}$. The morphology of $30 \% \mathrm{KOH} / \mathrm{ZrO}_{2}$-Bent changed to an amorphous structure because the structure of the pillared bentonite was broken. It is supported by the data rystallinity on XRD. Excess potassium at $30 \mathrm{wt} \%$ covers all pores and pillared bentonite surface, thus it affects to the growth of the particles. The existence of potassium oxide impregnated in $\mathrm{ZrO}_{2}$-Bentonite was reinforced by using EDX. The characterization result of the catalyst with the imposition of $\mathrm{KOH}$ (20-30 wt \%) are respectively $12.93 \%, 17.69 \%$ and 6:04\%.

\begin{tabular}{|c|c|}
\hline Catalyst & $\mathrm{K}(w t \%)$ \\
\hline $20 \% \mathrm{KOH} / \mathrm{ZrO}_{2}-\mathrm{Bent}$ & 12.93 \\
\hline $25 \% \mathrm{KOH} / \mathrm{ZrO}_{2}$-Bent & 17.69 \\
\hline $30 \% \mathrm{KOH} / \mathrm{ZrO}_{2}$-Bent & 6.40 \\
\hline
\end{tabular}

\section{Palm Oil Transesterification}

The activities of $\mathrm{KOH} / \mathrm{ZrO}_{2}$-Bentonite as heterogeneous base catalysts which have different base strength were tested in the transesterification reaction of palm oil.

Transesterification was performed under the conditions which was equal to the weight of the catalyst-used $3 \%$ of heavy oil. Based on the data in Table 3, the highest conversion of biodiesel product using a catalyst of $25 \% \mathrm{KOH} / \mathrm{ZrO}_{2}$-Bent is $81 \%$ with a mole ratio methanol:oil $12: 1$ and temperature of $65{ }^{\circ} \mathrm{C}$ which is proceed for $3 \mathrm{~h}$, Table 3 reveals the number of loading $\mathrm{KOH}$ from $20-30$ wt\% which increases the yield of the highest biodiesel (81\%) obtained for the loading of $\mathrm{KOH} 25 \mathrm{wt} \%$ on pillared bentonite material. However, when the amount of $\mathrm{KOH}$ increased as much as $30 \mathrm{wt} \%$; biodiesel product decreased. This is due to the agglomeration occurs because the excess of $\mathrm{KOH}$ alkaline led to a decrease in surface area of the catalyst, so that its activity is reduced. Besides, loading amount of $\mathrm{KOH}$ is high (30 wt \%) caused the formation of a new phase (Al-OK) which has properties alkalinity and catalytic activity is lower than the phase $\mathrm{K}_{2} \mathrm{O}$,7,9. Mole ratio of methanol:oil also affects to biodiesel product where in the mole ratio of methanol: oil 15:1 affects to declining on the conversion of biodiesel products due to the separation of the glycerol becomes more difficult $^{7}$. GC-MS analysis was carried out on the conversion of palm oil biodiesel products of the highest $(81 \%)$ to identify the components methyl ester compound contained qualitatively presented in Figure 6.

The result of GC analysis shows 6 peaks were detected as methyl ester which indicates the existences of 6 methyl ester. Each GC peak is analyzed by MS, it is derived methyl esters which is contained in biodiesel products of palm oil including: methyl laurate $(0.70 \%)$, methyl myristate $(1.99 \%)$, methyl palmitate $(49.78 \%)$, methyl stearate $(2.76 \%)$, methyl oleic (35.41\%) and methyl linoleic (9.35\%)

\section{Biodiesel Characterization}

Characteristic results of biodiesel from palm oil are shown in Table 4.

Table 3: Transesterification result of Palm oil using $\mathrm{KOH} / \mathrm{ZrO}_{2}$-Bentonite

\begin{tabular}{lcccc}
\hline Catalyst & $\begin{array}{c}\text { MeOH//oil } \\
\text { molar ratio }\end{array}$ & $\begin{array}{c}\text { Amount } \\
\text { of catalyst } \\
(\%)\end{array}$ & $\begin{array}{c}\text { Reaction } \\
\text { Time }(\mathrm{h})\end{array}$ & $\begin{array}{c}\text { Conversion } \\
\text { of biodiesel (\%) }\end{array}$ \\
\hline $20 \% \mathrm{KOH} / \mathrm{ZrO}_{2}$-Bent & $15: 01$ & 3 & 3 & 55 \\
$25 \% \mathrm{KOH} / \mathrm{ZrO}_{2}$-Bent & $12: 01$ & 3 & 3 & 74.65 \\
& $9: 01$ & 3 & 3 & 40 \\
& $15: 01$ & 3 & 3 & 64 \\
$30 \% \mathrm{KOH} / \mathrm{ZrO}_{2}-$ Bent & $12: 01$ & 3 & 1 & 50 \\
& $12: 01$ & 3 & 2 & 60 \\
& $12: 01$ & 3 & 3 & 81 \\
& $15: 01$ & 3 & 2 & 61.5 \\
\hline
\end{tabular}

* SNI 04-7182-2006 


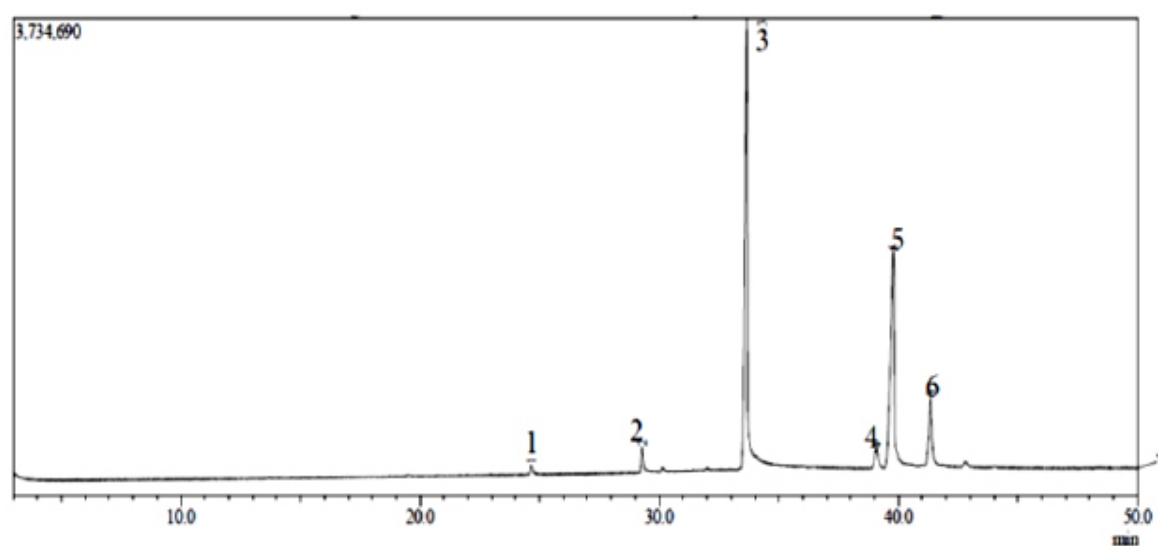

Fig. 6. Chromatogram of biodiesel Palm oil

Table 4: The properties of biodiesel produced in this experiment

\begin{tabular}{|c|c|c|c|}
\hline Parameter & Diesel oil *) & ASTM & Palm oil biodiesel \\
\hline Specific density $60 / 60^{\circ} \mathrm{F}$ & $0,85-0,92$ & $870-900$ at $15^{\circ} \mathrm{C}$ & 0,8771 \\
\hline Kinetic viscosity on $40^{\circ} \mathrm{C}, \mathrm{mm}^{2} . \mathrm{s}^{-1}$ & $2,3-6,0$ & $1.9-6.0$ & 5.730 \\
\hline Pour point, ${ }^{\circ} \mathrm{C}$ & Maks. 18 & 15 to 10 & 9 \\
\hline Flash point, ${ }^{\circ} \mathrm{C}$ & Min. 100 & Min. 130 & 165 \\
\hline Cloud point, ${ }^{\circ} \mathrm{C}$ & Max. 18 & 3 to 12 & 15 \\
\hline Water content, \%vol & Max. 0,05 & Max. 0.03 & trace \\
\hline
\end{tabular}

The viscosity of biodiesel fuel is 5.730 $\mathrm{mm}^{2} . \mathrm{s}^{-1}$. It gives a significant influence on the performance of injector and atomization of the fuel. Likewise, the density of biodiesel is as desired. The pour point and cloud point of biodiesel also meet the standards as a fuel. High pour point made a difficulty of ignited engine at low temperatures. The Flash point is related to the evaporation of the fuel. It is because flash point of palm oil biodiesel is higher than what is written in ISO 2006, consequently making it safe for storage purpose for a long time. Therefore, it can be used as substitution fuel for diesel engines.

\section{CONCLUSION}

$\mathrm{KOH} / \mathrm{ZrO}_{2}$-Bentonite from synthesis product can be used as a heterogeneous base catalyst in the transesterification reaction of palm oil. The results of transesterification of palm oil using the catalyst $\mathrm{KOH} / \mathrm{ZrO}_{2}$-Bentonite produced biodiesel with the optimum conversion of $81 \%$ was under the reaction conditions of $65^{\circ} \mathrm{C}$, molar ratio methanol: oil $12: 1$, and the weight of the catalyst used at $3 \%$ for $25 \% \mathrm{KOH} / \mathrm{ZrO}_{2}$-Bent.

\section{ACKNOWLEDGEMENT}

The financial support from DRPM Kemenristek Dikti under Hibah Disertasi Doktor scheme research granted in 2017 is gratefully acknowledged.

\section{REFERENCES}

1. Alves, H.J.; da Rocha, A.M.; Monteiro, M.R.; Moretti, C.; Cabrelon, M.D.; Sclwengher, C.A.; and Milinsk, M.C. Appl. Clay Sci., 2014, 91-92, 98-104.

2. Hasanudin, M; Said, M; Faizal, M. H. D.;
Wijaya, K. Sustainable Environ. Res., 2012, 22, 395-400.

3. Soetaredjo, F. E.; Ayucitra, A.; Ismadji, S.; Maukar, A. L. Appl. Clay Sci., 2011, 53, 341-346. 
4. Wijaya, K.; Iqmal, T; Ahmad, B., Indones. J. Chem., 2002, 2, 12-21.

5. Nagendrappa, G., Resonanc., 2002, 7, 64-77.

6. de Oliveira, A. D. N.; da Silva Costa, L. R.; de Oliveira Pires, L. H.; do Nascimento, L.A.S.; Angélica, R. S.; da Costa, C. E. F.; Zamian, J. R.; da Rocha Filho, G. N. Fuel., 2013, 103, 626-631.

7. Noiroj, K.; Intarapong, P.; Luengnaruemitchai, A.; Jai-In, S. J. Renewable Energy., 2009, 34, 1145-1150.

8. Rashtizadeh, E.; Farzaneh, F.; Ghandi, M. Fuel., 2010, 89, 3393-3398.

9. Agarwal, M.; Chauhan, G.; Chaurasia, S. P.; Singh, K., J. Taiwan. Inst. Chem. Eng., 2012, 43, 89-94.

10. Intarapong, P.; Jindavat, C.; Luengnaruemitchai, A.; Samai, J-I., Int. J. Green Energy., 2014, 11, 987-1001.
11. Takase, M.; Zhang, M.; Feng, W.; Chen, Y., Zhao, T.; Cobbina, S. J.; Liuqing, Y.; Wu, X., Energy Convers. Manage., 2014, 80, 117-125.

12. Xie, W.; Lie, H. J. Mol. Catal. A. Chem., 2006, 255, 1-9.

13. Suseno, A.; Wijaya, K.; Trisnunaryanti, W.; Shidiq, M. Asian. J. Chem., 2015, 27, 26192623.

14. Utubira, Y.; Wijaya, K.; Triyono; Kunarti, E. S. Int. J. ChemTech. Res., 2016, 9, 475-482.

15. Sekewael, S.J.;Wijaya, K.; Triyono; Budiman, A. Asian. J. Chem., 2016, 28, 2325-2330.

16. Singh, V.;Sapehiyia, V.; Kad, G. L., J. Mol. Catal. A: Chem., 2004, 210, 119-124.

17. Fatimah, I.; Rubiyanto, D.; Huda, T., Int. J. Chem. Eng., 2014.

18. Qiu, F.; Li, Y, Yang, D.; Li, X.; Sun, P., Appl. Energy., 2011, 288, 2050-2055. 